\title{
Tuning Strategies for Online-Adaptive PI Controllers
}

\author{
L. Däubler, C. Bessai and O. Predelli \\ IAV GmbH - Ingenieurgesellschaft Auto und Verkehr, Nordhoffstraße 5, 38518 Gifhorn - Germany \\ e-mail: lorenz.daeubler@iav.de - christian.bessai@iav.de - oliver.predelli@iav.de
}

Résumé - Stratégies de réglage des contrôleurs PI à adaptation en ligne - Afin de respecter les limitations à venir en matière de $\mathrm{NO}_{\mathrm{X}}$ pour les moteurs diesel, les chercheurs ont étudié de nouvelles stratégies de combustion comme la combustion basse température ou l'autoallumage par compression. Afin que ces stratégies de combustion fonctionnent efficacement, il est primordial que le contrôleur du passage de l'air assure un suivi simultané de la pression d'admission et du taux EGR et que le comportement passager en circuit fermé soit réglable en fonction des exigences relatives aux émissions. Afin d'assurer ces tâches, nous avons élaboré une structure de contrôleur d'alimentation entrante/PI à adaptation en ligne (de type MBCAP, Model Based Control of Air Path) associé à une routine d'adaptation des paramètres basée sur le modèle. Cette routine se base sur l'emplacement des pôles de passage de l'air en circuit fermé. Les pôles du passage de l'air en circuit fermé sont calculés en ligne grâce à un modèle de traitement thermodynamique à paramètre variable linéarisé (modèle LPV). Cet article présente le contrôleur MBCAP, la structure du modèle thermodynamique sous jacent, une stratégie de réglage de ce contrôleur et les résultats du test expérimental.

\begin{abstract}
Tuning Strategies for Online-Adaptive PI Controllers - In order to meet future $N O_{X}$ emission limits for Diesel engines, researchers have been investigating new combustion strategies such as Low Temperature Combustion and Homogenous Charge Compression Ignition. For these combustion strategies to work effectively, it is crucial that the air path controller provides accurate simultaneous tracking of boost pressure and EGR rate and that transient closed-loop behaviour be adjustable according to emissions related requirements. To fulfill these tasks we developed an online-adaptive PI/feed-forward controller structure (MBCAP, Model Based Control of Air Path) with a model-based parameter adaptation routine. This routine is based on the placement of the closed-loop air path poles. The closed-loop air path poles are calculated online through a linearized parameter variable thermodynamic process model (LPV model). This paper presents the MBCAP controller, the underlying thermodynamic model structure, a tuning strategy for this controller and experimental test results.
\end{abstract}




\section{DEFINITIONS, ACRONYMS, ABBREVIATIONS}

$\begin{array}{ll}\text { ADCS } & \text { Advanced Diesel Combustion System } \\ \text { C } & \text { compressor } \\ \text { CL } & \text { closed loop } \\ \text { D } & \text { differential } \\ \text { DPF } & \text { diesel particulate filter } \\ \text { ECU } & \text { electronic control unit } \\ \text { EGR } & \text { exhaust gas recirculation } \\ \text { ENG } & \text { engine } \\ \text { EX } & \text { exhaust manifold } \\ \text { fric } & \text { friction }\end{array}$

HCCI homogeneous charge compression ignition

HOCCOS Homogeneous Combustion Controller Software

I integral

IM intake manifold

LPV linear parameter variant

LTC low temperature combustion

LTI linear time invariant

MAF mass air flow

MBCAP Model Based Control, Air Path

$\mathrm{N}$ nitrogen

n normalized

O oxygen

OL open loop

$\mathrm{P} \quad$ proportional

petl precontrol

PI proportional-integral

set setpoint

$\mathrm{T} \quad$ turbine

TC turbo charger

VGT variable geometry turbine

$A_{i, e f f} \quad$ effective valve area of throttle $i$

$B \quad$ boundary

$C(\ldots) \quad$ characteristic map or curve

$C(s) \quad$ controller transfer function

$c_{p} \quad$ heat capacity, isobar

D damping

$f \quad$ function

$h \quad$ enthalpy

$K_{i} \quad$ controller gain, process gain, tuning factor

$k_{T C} \quad$ turbo charger friction coefficient

$M \quad$ torque

$\dot{m}_{i} \quad$ mass flow through throttle or into volume $i$

$n \quad$ index variable

$n_{E N G} \quad$ engine speed

$P \quad$ power

$P(s) \quad$ process or plant transfer function

$\begin{array}{ll}p & \text { complex pole } \\ p_{i} & \text { pressure in the volume } i \\ R^{*} & \text { real specific gas constant } \\ s & \text { complex frequency } \\ s_{V G T} & \text { EGR valve actuator signal } \\ s_{V G T} & \text { VGT actuator signal } \\ T_{i} & \text { temperature in the volume } i \\ T_{1} & P T_{1} \text { time constant } \\ x & \text { state variable } \\ \mathbf{x} & \text { state vector } \\ \varepsilon & \text { small region within a map C } \\ \eta & \text { efficiency } \\ \Theta & \text { inertia } \\ \kappa & \text { isentropic exponent } \\ \omega_{0} & \text { natural frequency } \\ \omega_{T C} & \text { turbo charger speed } \\ \pi_{i} & \text { pressure ration over component } i \\ \psi & \text { flow function }\end{array}$

\section{INTRODUCTION}

In order to meet future $\mathrm{NO}_{\mathrm{X}}$ emission limits for Diesel engines, researchers have been investigating new combustion strategies such as Low Temperature Combustion (LTC) and Homogeneous Charge Compression Ignition (HCCI). Running a Diesel engine with a homogenized air/fuel mixture presents a major control challenge. In order to reduce the combustion oxygen ratio, very high EGR rates are necessary to compensate for the high ignition quality of diesel fuel. However, experience shows that these combustion processes are very sensitive to cyclical fluctuations in the thermodynamic state [2]. Small deviations from the desired state can cause significant emission changes, shifts in heat release phasing and excessive combustion noise.

For these combustion strategies to work effectively, it is crucial that the air path controller provides accurate simultaneous tracking of boost pressure and EGR rate and that transient closed-loop behaviour (e.g. damping and overshoot) be adjustable according to emissions related requirements. To fulfill these tasks we developed an online-adaptive PI/feedforward controller structure (MBCAP, Model Based Control of Air Path) with a model-based parameter adaptation routine. This routine is based on the placement of the closedloop air path poles. The closed-loop air path poles are calculated online through a linearized parameter variable thermodynamic process model (LPV model). This pole placement routine allows the combustion-related closed-loop performance specifications to be met in an effective and direct way.

Compared to the gain-scheduling methods that are implemented in production engine management systems, the online adaptation reduces the calibration effort drastically. 
The controller and the tuning approach were validated on a test engine used to demonstrate IAV's Advanced Diesel Combustion System (ADCS) for HCCI/LTC combustion studies [6].

This paper presents the MBCAP controller, the underlying thermodynamic model structure, a tuning strategy for this controller, and experimental test results.

\section{ENGINE SETUP}

One of the test engines used in the IAV ADCS is a 4-cylinder 2.2 liter displacement engine. During the course of development, the engine evolved to have a 2-stage turbocharging system, cylinder-selective EGR valves, piezo-inline-injectors, a low-temperature coolant circuit, and an in-cylinder pressure indication system. In order to control a system with such complexity, we developed a model based control strategy that can be implemented simultaneously during the engine prototyping and setup phases.

For a better understanding of the underlying modeling and control approach, we start with a simplified engine setup with standard air path components including one EGR valve, an intake air throttle and a variable geometry turbine, shown in Figure 1.

In addition to the air path components, Figure 1 defines the relevant thermodynamic state variables, the actuator signals for EGR and VGT control and the measurement values. The control of the intake air throttle is not examined in this paper.

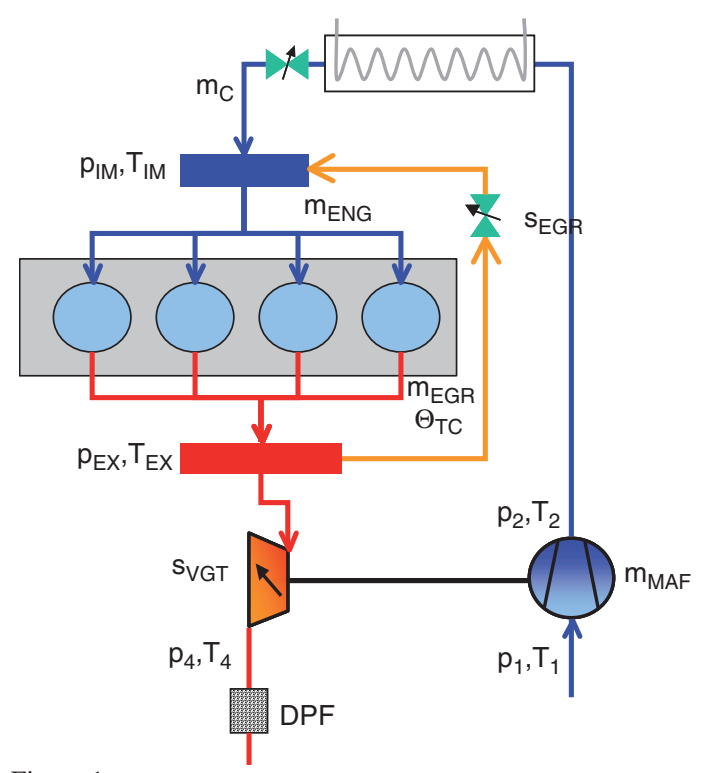

Figure 1

IAV's ADCS 4 cylinder engine, simplified air path setup.

\section{THERMODYNAMIC MODELING OF THE AIR PATH}

Fundamental thermodynamic principles like the ideal gas equation and the conservation of energy and mass can be applied to derive non-linear ordinary differential equations for the intake pressure, the exhaust pressure and the EGR mass flow. These differential equations are also the basis for the linearized air path model described in Section 3.

It is assumed that the compressed air $\dot{m}_{c}$ and the recirculated exhaust gas $\dot{m}_{E G R}$ flowing into the intake manifold behave like ideal gases. Deriving the ideal gas equation results in the following differential equation for the intake manifold pressure $p_{I M}$.

$$
\dot{p}_{I M}=\frac{R^{*} \cdot T_{I M}}{V_{I M}} \cdot\left(\dot{m}_{C}+\dot{m}_{E G R}-\dot{m}_{E N G}\right)
$$

where $R^{*}$ is the real specific gas constant according to [8]. $V_{I M}$ is the intake manifold volume and $T_{I M}$ is the intake manifold temperature. It is assumed, that temperature changes can be neglected compared to pressure changes.

The compressed mass flow is given through a characteristic curve $C$ specified by the turbocharger manufacturer:

$$
\dot{m}_{C}=C\left(\omega_{T C}, \pi_{C}, T_{1}\right) \text { with } \pi_{C}=\frac{p_{2}}{p_{1}}
$$

The main influences on the compressor mass flow are the turbo charger speed $\omega_{T C}$, the pressure ratio $\pi_{C}$ and the inlet temperature $T_{1}$.

Similarly, the engine mass flow is also given through a characteristic map $C$ :

$$
\dot{m}_{E N G}=C\left(n_{E N G}, p_{I M}, T_{I M}\right)
$$

The main influences for the engine mass flow are the engine speed $n_{E N G}$, the intake pressure $p_{I M}$ and the intake temperature $T_{I M}$.

Unlike the engine and compressor mass flows, the mass flow through the $E G R$ valve $\dot{m}_{E G R}$ can be calculated analytically by applying the thermodynamic principle of isentropic expansion [5]:

$$
\dot{m}_{E G R}=A_{E G R, e f f} \cdot \frac{p_{E X}}{\sqrt{R^{*} \cdot T_{E X}}} \cdot \psi_{E G R}
$$

The effective valve area $A_{E G R, e f f}$ depends on the acutator signal $s_{E G R}$. The flow function $\psi_{E G R}$ is given as:

$$
\psi_{E G R}=\sqrt{\frac{2 \kappa}{\kappa-1}\left(\pi_{E G R}^{\frac{2}{\kappa}}-\pi_{E G R}^{\frac{\kappa+1}{\kappa}}\right)}, \pi_{E G R}=\left(\frac{p_{I M}}{p_{E X}}\right)
$$

with the isentropic exponent $\kappa$. 
The differential equation for the exhaust pressure is derived analogously to (1):

$$
\dot{p}_{E X}=\frac{R^{*} \cdot T_{E X}}{V_{E X}} \cdot\left(\dot{m}_{E N G}+\dot{m}_{F u e l}-\dot{m}_{T}-\dot{m}_{E G R}\right)
$$

As in (2), the turbine mass flow $\dot{m}_{T}$ in (6) is given by a characteristic map with the VGT actuator signal $s_{V G T}$ as an additional input parameter.

As one can easily see, the turbo charger speed $\omega_{T C}$ in (2) is an important parameter for determining turbo charger mass flows and thus the intake and exhaust manifold pressures. As shown in the next equations, the turbocharger speed can be estimated based on mechanical and thermodynamic relations.

First we calculate the torque balance over the turbo charger shaft as follows:

$$
\dot{\omega}_{T C}=\frac{1}{\Theta_{T C}} \cdot\left(M_{T}-M_{C}-M_{F r i c}, T C\right)
$$

The torque $M_{T}$ generated by the turbine can be determined through the turbine power $P_{T}$.

$$
M_{T}=P_{T} / \omega_{T C}
$$

The turbine power $P_{T}$ in (8) is given through the following equation:

$$
P_{T}=\dot{m}_{T} \cdot \Delta h_{i s, T} \cdot \underbrace{\eta_{i s, T} \cdot \eta_{m, T}}_{\eta_{T}}
$$

where the isenstropic enthalpy loss $\Delta h_{i s, T}$ over the turbine can be calculated as:

$$
\Delta h_{i s, T}=c_{p} T_{E X}\left[1-\left(\frac{p_{4}}{p_{E X}}\right)^{\frac{\kappa_{T}+1}{\kappa_{T}}}\right]
$$

and the total turbine efficiency can be read from a characteristic turbocharger map.

Since the turbine mass flow and efficiency in (9) are given as characteristic maps, the turbine power itself is also a characteristic map. Figure 2 on the following page shows the map of the normalized turbine power over $\omega_{T C}$ and $\pi_{C}$ with a $s_{V G T}$ value of $40 \%$.

The compressor load $M_{C}$ in (7) can be determined analogously to (8).

For the missing friction torque $M_{F r i c, T}$ in (7) one can formulate a Coulomb friction law (11). In [3] it is shown how to determine this friction coefficient:

$$
M_{F r i c, T C}=k_{T C} \cdot \omega_{T C}
$$

The presented thermodynamic and mechanical equations (1) to (11) cover the system behaviour of the intake manifold, the exhaust manifold and the turbocharger. In the next

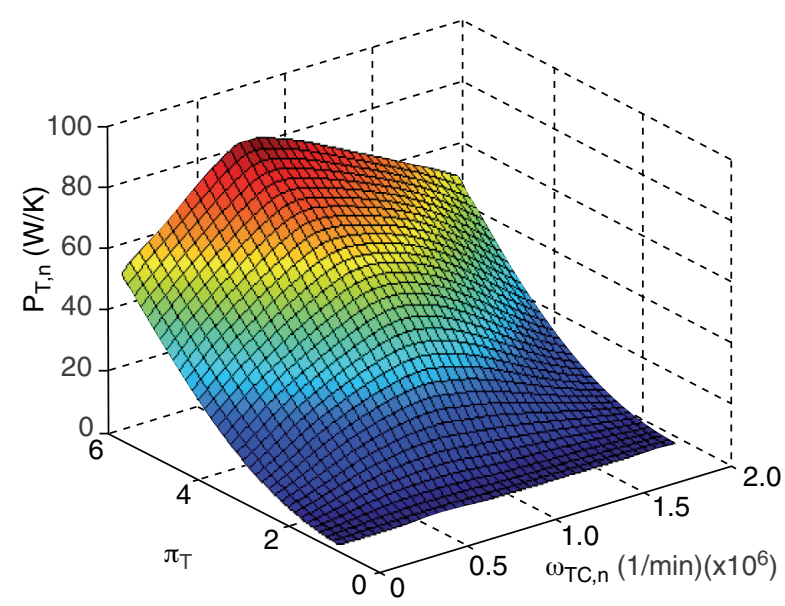

Figure 2

Normalized turbine power $P_{T, n}$ over turbine speed and pressure ratio, VGT $40 \%$.

section, it is shown how these equations can be processed to produce a linear parameter variant model.

\section{LINEARIZED AIR PATH MODEL}

Standard controller design approaches are based on linear, time invariant systems (LTI), but the equations presented in Section 2 show highly non-linear system behaviour. Thus, one can linearize the thermodynamic/mechanical air path equations in order to get a linear system with time varying parameters (LPV system). Since the linearized system behaviour is only valid in a limited region around a specific operating point, the LPV model must be updated online. This is done within a periodic update routine with an update sample time $T_{U D}$.

First, we present the generic linearization approach for an arbitrary non-linear function and extend this approach to differential equations. Then this approach is applied to the thermodynamic equations in Section 2 to produce a linearized, parameter variant system model.

\subsection{Generic Linearization Approach}

Given an arbitrary non-linear equation, we can derive a linearized equation that approximates the system behaviour and that is valid only near a specific operating point.

The generic linearization approach is based on a gradient method [1].

Let's focus on a non-linear, multi-dimensional homogenous function $f$ in the variables $\mathbf{x}=\left(x_{1}, \ldots, x_{\mathrm{n}}\right)$

$$
f\left(x_{1}, \ldots, x_{n}\right)=0
$$




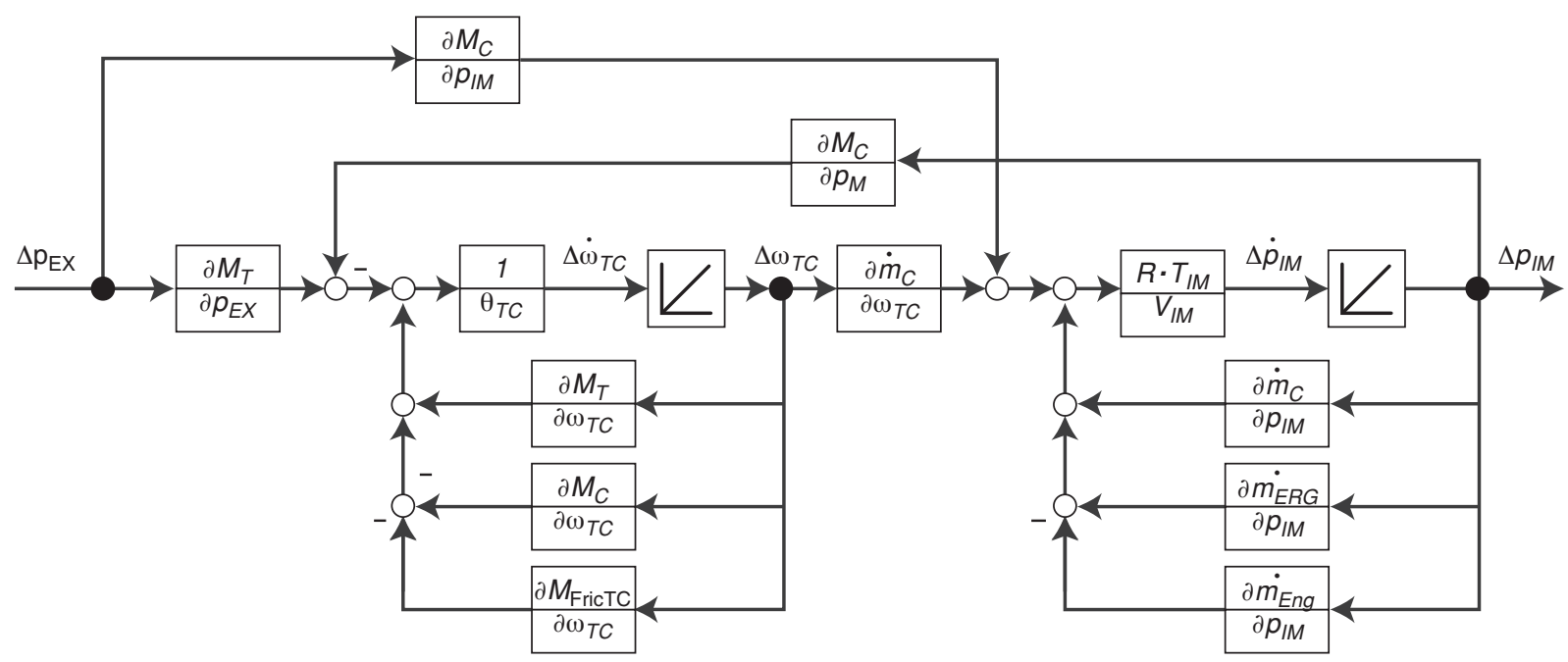

Figure 3

Linearized block diagram for the exhaust/intake manifold process.

The function $f$ can be approximated in a limited region $\Delta \mathbf{x}=\left(x_{1}-x_{1,0}, \ldots, x_{n}-x_{n, 0}\right)$ around the operating point $\mathbf{x}_{0}=$ $\left(x_{1,0}, \ldots, x_{n, 0}\right)$ with the following equation:

$$
f(\mathbf{x}) \approx f\left(\mathbf{x}_{\mathbf{0}}\right)+\Delta f\left(\mathbf{x}_{\mathbf{0}}, \Delta \mathbf{x}\right)
$$

where $\Delta f$ is the gradient of $f$ in $\mathbf{x}_{0}$ :

$$
\Delta f\left(\mathbf{x}_{0}, \Delta \mathbf{x}\right)=\frac{\partial f}{\partial x_{1}}\left(\mathbf{x}_{0}\right) \cdot \Delta x_{1}+\cdots+\frac{\partial f}{\partial x_{n}}\left(\mathbf{x}_{0}\right) \cdot \Delta x_{n}
$$

Taking (12) into account, the terms $f\left(\mathbf{x}_{0}\right)$ and $\Delta f\left(\mathbf{x}_{0}, \Delta \mathbf{x}\right)$ in (13) both become 0 :

$$
\Delta f\left(\mathbf{x}_{0}, \Delta \mathbf{x}\right)=0
$$

Now we consider the case of an ordinary differential equation in $t$, where the state $\mathbf{x}$ in (12) contains time derivatives $x_{j}$ with:

$$
x_{j}=\frac{d}{d t} x_{i}=\dot{x}_{i}
$$

Then each component $\Delta x_{j}$ of the region $\Delta \mathbf{x}$ can be calculated as follows:

$$
\Delta x_{j}=\frac{d}{d t} x_{i}-\frac{d}{d t} x_{i, 0}=\frac{d}{d t}\left(x_{i}-x_{i, 0}\right)=\Delta \dot{x}_{i}
$$

Thus, the linearization approach in (13), (14) holds even for ordinary differential equations.

In the next section we show how the linearization approach can be applied to the thermodynamic/mechanical differential equations (1), (6) and (7) describing the Diesel engine air path process.

\subsection{Application to the Air Path Process}

As seen in Section 2, the single terms of the differential equations (1), (6) and (7) are given either as analytical functions or as characteristic maps. Depending on these types of components, the partial derivatives in (14) have to be calculated in different ways.

Characteristic maps, like that in (2), can be processed by a geometric derivation method:

$$
\frac{\partial C}{\partial x_{1}}\left(\mathbf{x}_{\mathbf{0}}\right) \approx \frac{C\left(x_{1,0}+\varepsilon, \cdots, x_{n, 0}\right)-C\left(x_{1,0}-\varepsilon, \cdots, x_{n, 0}\right)}{2 \varepsilon}
$$

Given a fixed data grid on which the map $C$ is defined, $\mathbf{x}_{\mathbf{0}}$ and $\varepsilon$ must be chosen such that all values of $\mathbf{x}_{\mathbf{0}}+/-\varepsilon$ lay on the fixed data grid. The result of this geometric derivation method is a characteristic map again.

Besides the geometric derivation method for characteristic maps and curves, the analytical functions like (4) can be derived directly by applying conventional calculus rules [7].

Figure 3 shows the resulting block diagram of the linearized differential equations (1) and (7) as a linear, parameter-varying model (LPV). According to the block diagram the exhaust pressure $p_{E X}$ directly affects the turbocharger speed $\omega_{T C}$.

The turbocharger speed in turn has an effect on the compressor mass flow and thus the intake manifold pressure $p_{I M}$.

The block diagram also reveals that the exhaust pressure has a direct feed-through effect on the intake manifold 


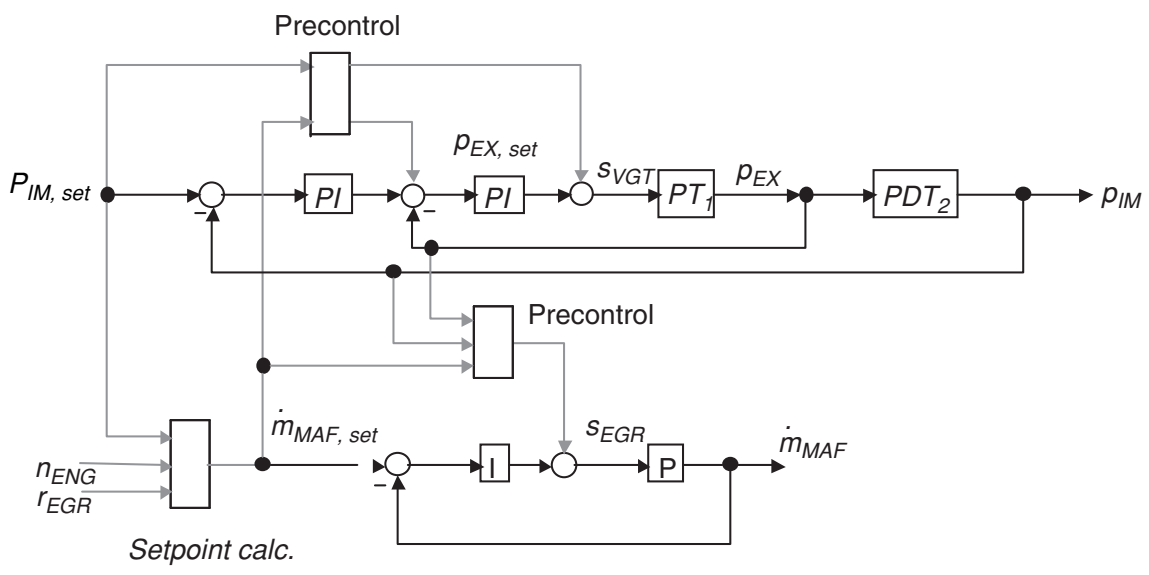

Figure 4

MBCAP, Control Structure.

pressure over the EGR mass flow, which deeply impacts any Diesel air path control design approach.

By linearizing the differential equation (6), the block diagram in Figure 3 can easily be extended so that it reflects the whole air path causality beginning at the actuator signals $s_{V G T}$ and $s_{E G R}$ (see Fig. 1) and ending at the intake manifold pressure $p_{I M}$ and the EGR mass flow $\dot{m}_{E G R}$. This extended linearized block diagram is the foundation for the control approach presented in Section 4.

\section{ADAPTIVE CONTROL APPROACH}

Given the linearized block diagram describing the air path process, we designed the model based control approach MBCAP (Model Based Control, Air Path) reflected in Figure 4.

\subsection{Control Structure}

The main characteristic of this controller is the pair of cascaded PI-controllers for the exhaust and intake manifold pressures and the one $I$-controller for the air mass flow, (see Fig. 4). This design combines the easy implementation and parametrization of $P I$-controllers with the decoupling effects of a cascading structure.

The boost pressure precontrol is shown in detail in Figure 5. It is based on the compressor and turbine maps. The input variables are the airpath setpoints, the inlet temperature $T_{1}$ and the fuel mass flow $\dot{m}_{\text {Fuel }}$. Via the compressor and turbine power balance with regard to the turbine mass flow setpoint $\dot{m}_{T, s e t}$ the exhaust back pressure precontrol setpoint $p_{E X, \text { set, } p c t l}$ and the VGT actuator feed-forward output $s_{V G T, p c t l}$ are calculated.

The EGR precontrol is the result of the inversion of Equation (4). By using the characteristic curve of the EGR actuator the EGR actuator feed-forward output $s_{E G R, p c t l}$ is determined.

The setpoint calculation block in Figure 4 estimates the appropriate air mass flow setpoint $\dot{m}_{M A F \text {,set }}$ depending upon the desired EGR rate $r_{E G R}$, intake manifold pressure $p_{I M}$ and engine speed $n_{E N G}$.

In order to compensate for undesired zeros appearing in the numerator of the tracking transfer functions and to smooth the input signals, the control approach is comprised

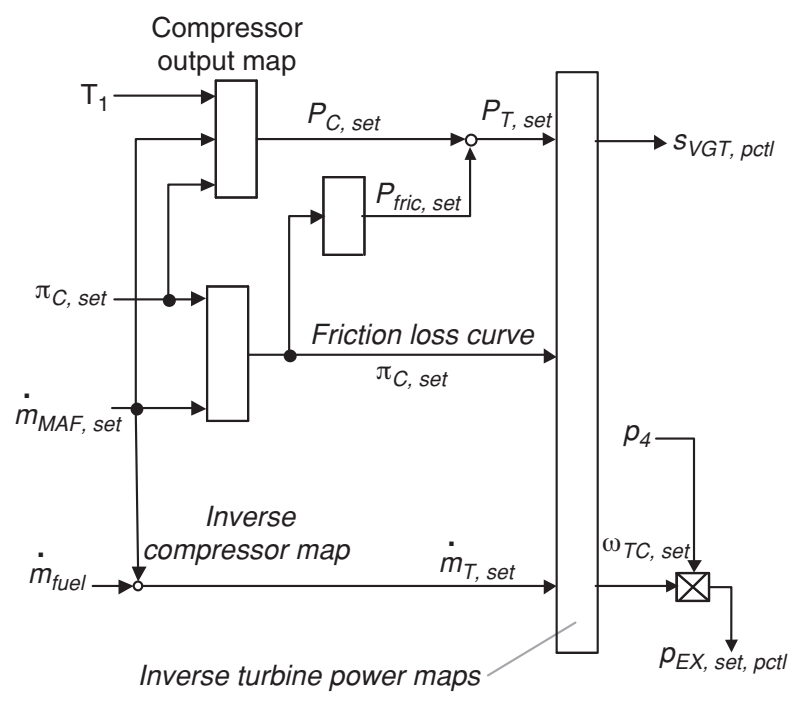

Figure 5

Turbocharger precontrol. 
of linear 1st-order low-pass filters blocks that are not shown in Figure 4.

\subsection{Control Parameter Adaptation}

As shown in Section 3, the air path process can be described as a linear parameter-varying model. Based on the known parameter variation over time, one can design an online control parameter adaptation routine for the $P I$ and $I$ controllers in Figure 4.

Given a $P T_{1}$ plant controlled by a $P I$ controller, we define the following transfer functions for the process $P(s)$ and the controller $C(s)$ :

$$
P(s)=\frac{K_{S}}{\left(s T_{1}+1\right)}, C(s)=K_{P}+\frac{K_{I}}{s}
$$

$\mathrm{T} \mathrm{h}$ e closed-loop poles $p_{C L, 1}$ and $p_{C L, 2}$ of the controlled plant are defined as:

$$
p_{C L 1,2}=-\omega_{0, C L} D \pm j \sqrt{1-D^{2}} \omega_{0, C L}
$$

with the closed-loop natural frequency $\omega_{0, C L}$ and the damping $D$.

In order to place the closed-loop poles in a specific position defined by $\left(\omega_{0, C L}, D\right)$, the $P I$ parameters must be adjusted to the following values:

$$
K_{P}=\frac{2 D \omega_{0, C L} T_{1}-1}{K_{S}}, K_{I}=\omega_{0, C L}^{2} \frac{T_{1}}{K_{S}}
$$

In order to apply the control parameter adaptation rules (21) to the linearized air path process shown in Figure 4, the $P D T_{2}$ block can be replaced by an equivalent $P T_{1}$ block, which shows the same numeric control deviation area [4].

\subsection{Tuning Strategy}

The online-adaptive PI controller strategy reduces the calibration effort drastically, but still allows the possibility of shaping the system behaviour by specifying $\left(\omega_{0, C L}, D\right)$ and thus properly placing the closed-loop poles. According to [4], there exist different approaches for the choice of $\left(\omega_{0, C L}, D\right)$ depending upon the desired trade-off between dynamics and damping.

To provide for sufficient control dynamics, we want to assure that the system reaches steady state after a defined attenuation time. According to linear system theory, this is guaranteed by limiting the real part of the closed-loop poles to a fixed attenuation boundary $B$ :

$$
\operatorname{Re}\left\langle p_{C L 1,2}\right\rangle=-\omega_{0, C L} D \leq \dot{!} B
$$
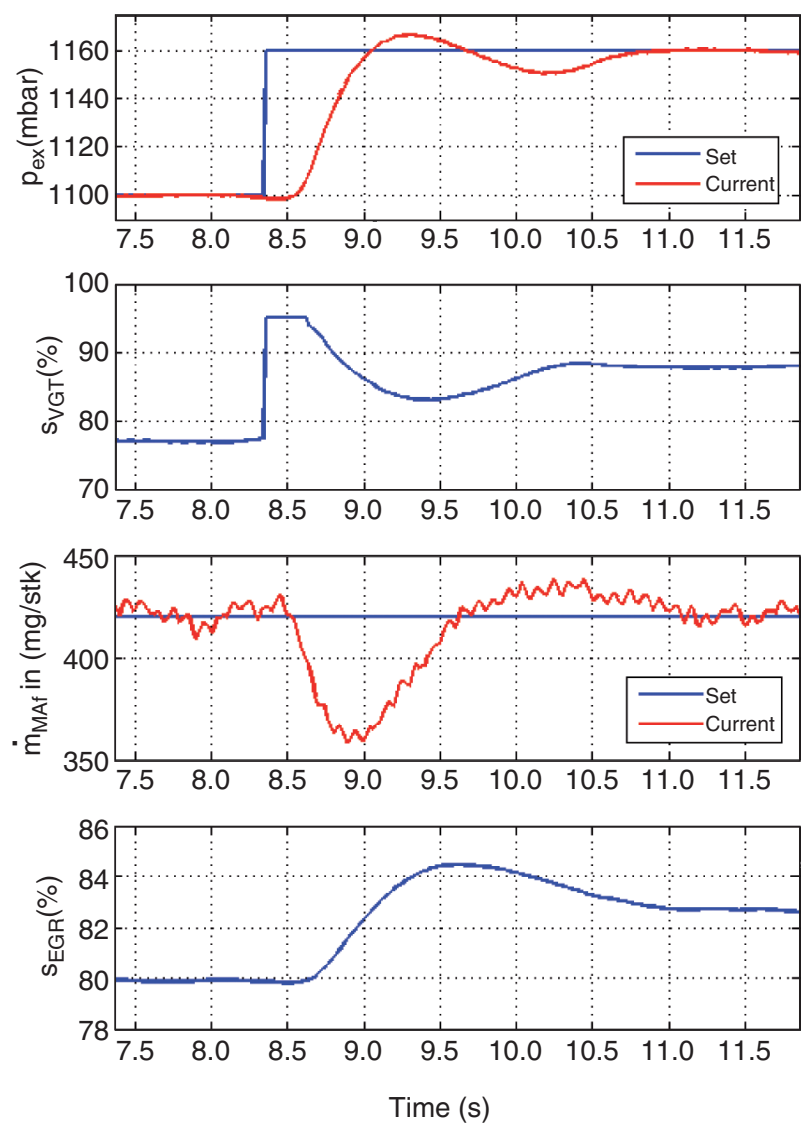

Figure 6

Exhaust pressure step response at $1200 \mathrm{~min}^{-1}$ engine speed, $52 \mathrm{Nm}$ load, $D=2$.

Now we set the default value for this boundary to the natural frequency $\omega_{0, O L}$ of the open loop process $P(s)$ in (19). In order to have an influence on the PI-controller behaviour we first provide a tuning factor $K_{v}$, which can be used to parametrize the attenuation boundary.

$$
\omega_{0, C L} D=K_{v} \cdot \omega_{0, O L}
$$

After setting the boundary through the real part of the closedloop poles, one can shape the system dynamics by adjusting the damping parameter $D$. With (23) it is assured that the controlled process reaches steady state conditions within a defined attenuation time.

\section{RESULTS}

The presented MBCAP control approach is implemented with MATLAB/Simulink and is embedded in IAV's ADCS 


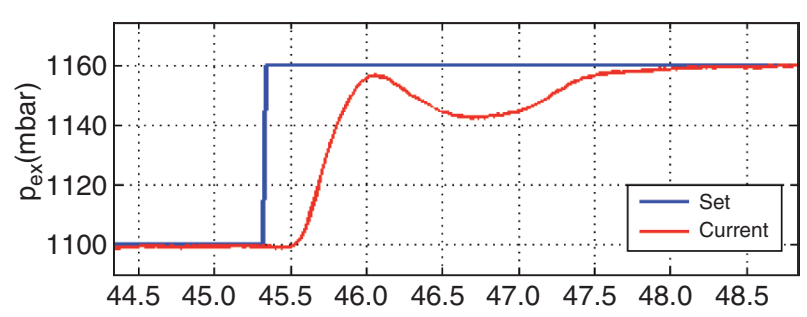

Figure 7

exhaust pressure step response at $1200 \mathrm{~min}-1$ engine speed, $52 \mathrm{Nm}$ load, $D=3$.

engine control software called HOCCOS (Homogeneous Combustion Control Software). HOCCOS is executed on a dSPACE rapid controller prototyping platform (MicroAutoBox) and runs without a bypass-ECU. Refer to [1] for a description of the complete control unit architecture. This controller prototyping platform provides for sufficient computation power to calculate the MBCAP's internal LPV model in a $10 \mathrm{~ms}$ time slice.

The ADCS prototype engine is equipped with the air path components described in Section 1. In this paper we present test results from the online-adaptive PI controller for the exhaust pressure induced by the VGT turbocharger (Fig.4).

Figure 6 shows an exhaust pressure step response, the VGT actuator signal $s_{V G T}$, the mass air flow disturbed by the $p_{E X}$ step, and the EGR actuator signal $s_{E G R}$ at low load and low engine speed.

The tuning factor $K_{v}$ is set to 1 , which fixes the absolute value of the real part of the closed-loop poles to the open loop natural frequency according to (23). The damping D is set to 2 . This was necessary because the first identification tests showed that the estimated process gain $K_{S}$ in (19) is in the presented engine operation point approximately 4 times smaller than the identified process gain.

Nevertheless, the tuning strategy for the online-adaptive controller allows shaping of the step response while keeping the attenuation time of approximately $2.6 \mathrm{~s}$. After this time, steady state is nearly reached.

Figure 7 shows the exhaust pressure step response with damping set to 3 .

As expected the controlled exhaust pressure shows significantly higher damping than figure 6 with no overshoot, but steady state is reached after the same attenuation time (2.6 s).

\section{CONCLUSION}

In this paper we have presented an online-adaptive control approach for a Diesel engine air path controller that allows shaping of the closed-loop behaviour through pole placement. The foundation for this adaptation approach is a linearized air path model provided as a block diagram. This block diagram can be derived from non-linear ordinary differential equations describing the thermodynamic and mechanical behaviour of the air path. The linearization approach is based on gradient computations. The onlineadaptive control approach was validated experimentally on a 4-cylinder Diesel engine.

Furthermore, we presented and evaluated a tuning strategy that guarantees a fixed attenuation time while varying the closed-loop system damping.

Future development and testing will focus on the transient air path behaviour in different drive cycles. Additionally, alternate tuning and design strategies like robust control will be examined.

\section{REFERENCES}

Däubler, L., Rempel, A., Gratzke, R., Predelli, O. (2005) Flexibles Motormanagement für innovative Brennverfahren, $M T Z$ Motortechnische Zeitschrift, 66, 9.

Kabitzke, J., Lautrich, G. , Sommer, A., Däubler, L., Rempel, A. (2005) Anforderungen an das Aufladesystem zur Erweiterung des Kennfeldbereiches eines Low-NOX-Brennverfahrens, 1. Tagung „Motorprozesssimulation und Aufladung “, Berlin, 2005.

Kessel, J.-K. (2003) Modellbildung von Abgasturboladern mit variabler Turbinengeometrie in schnellaufenden Dieselmotoren, $P h D$ Thesis, TU Darmstadt.

Leonhard, W. (1990) Einführung in die Regelungstechnik. Vieweg Verlag, Braunschweig.

Merker, G., Schwarz, C., Stiesch, G., Otto, F. (2004) Verbrennungsmotoren - Simulation der Verbrennung und Schadstoffbildung. B.G. Teubner Verlag, Wiesbaden.

Predelli, O., Matz, M., Brauer, M., Blechstein, A., Karstedt, J. (2005) Advanced Diesel Combustion System (ADCS) für PkwDieselmotoren - Brennverfahren und Steuerungskonzepte, 10. Tagung Der Arbeits - Prozess Des Verbrennungsmotors, Graz, 2005.

Bronstein, I. N., Semendjajew, K. A. (1991) Taschenbuch der Mathematik, Verlag Nauka, Moskau, B.G Teubner, Stuttgart/Leipzig, Verlag Harri Deutsch, Thun/Frankfurt.

Pucher, H. Motorprozesstechnik. Lecture Notes, Technical University Berlin.

Final manuscript received in October 2006 or distributed for profit or commercial advantage and that copies bear this notice and the full citation on the first page. Copyrights for components of this work owned by others than IFP must be honored. Abstracting with credit is permitted. To copy otherwise, to republish, to post on servers, or to redistribute to lists, requires prior specific permission and/or a fee: Request permission from Documentation, Institut français du pétrole, fax. +33147527078 , or revueogst@ifp.fr. 